Renal Unit, The Royal Infirmary, Manchester, UK DJA Goldsmith NP Mallick

Victoria University of Manchester, Manchester, UK ISD Roberts

Correspondence to $\mathrm{Dr}$ David JA Goldsmith, Trafford Department of Trafford Department of Sussex County Hospital, Eastern Road, Brighton BN2 5BE, UK

\section{Tingling extremities in a young man}

\author{
DJA Goldsmith, ISD Roberts, NP Mallick
}

A 20-year-old man had been referred with a three-year history of burning, tingling extremities, affecting the hands and feet equally. There was a basal level of discomfort, but attacks of much more severe symptoms would occur, often for hours at a time, associated with pallor of the extremities, and provoked by stress, exercise and cold. There was no seasonal variation in the symptoms. There were no other symptoms.

The patient had three sisters, one of whom had died from leukaemia, and another of whom had identical symptoms to the index patient. His father had committed suicide in his mid40s after a long depression and, his mother had died in her mid30s from a brain tumour and acute nephritis. Blood pressure was $110 / 70 \mathrm{mmHg}$, and the rest of the clinical examination was normal. Investigations were limited to haemoglobin, packed cell volume, albumin, globulin, urinalysis, and chest and cervical spine X-ray films, all of which were normal. A diagnosis of 'peripheral circulatory disturbance' was made, and advice given to wrap up in woollen mittens and socks. The patient was discharged. The symptoms continued unabated thereafter.

Twenty six years later, following a medical examination for a new job that had discovered + proteinuria on urine testing, the patient, now married with two children, one of whom has parasthesiae, was referred to a nephrologist for evaluation. A niece and a nephew had been diagnosed with 'nephritis' and parasthesiae, respectively. His only symptom was acroparasthesiae, less severe than before. Blood pressure was $145 / 72 \mathrm{mmHg}$. He had telangiectatic skin lesions in his umbilicus (figure 1 ). No other abnormal signs were detected. Urinalysis showed ++ protein and no blood; the urine was acellular; $24 \mathrm{~h}$ urine protein excretion was $3 \mathrm{~g}$ (selectivity index 0.18); plasma albumin was $34 \mathrm{~g} / \mathrm{l}$. All other biochemical, haematological and immunological parameters were normal, except for the erythrocyte sedimentation rate which was $52 \mathrm{~mm} / \mathrm{h}$. Excretory renal function was normal (urea $5.7 \mathrm{mmol} / \mathrm{l}$, creatinine $87 \mu \mathrm{mol} / \mathrm{l}$ ), as was a chest Xray. Renal ultrasound showed symmetrical normal-sized kidneys.

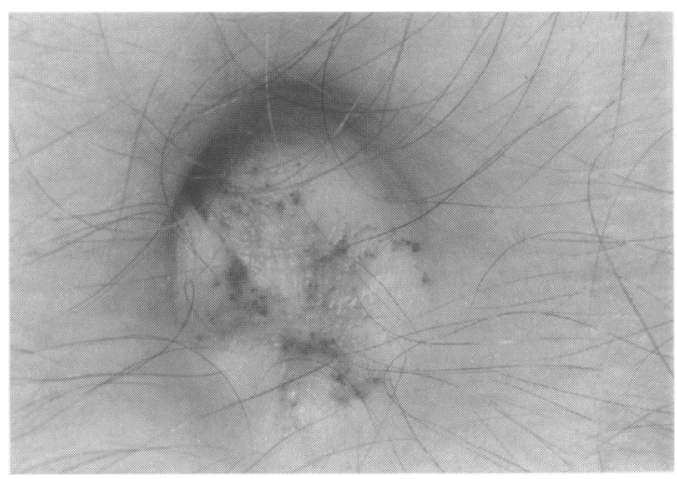

Figure 1 Telangiectatic lesions in the umbilicus 
Figure 2 Appearances of the renal biopsy. (A) light microscopy showing birefringent vacuolisation of visceral epithelial cells; (B) tubular epithelial vacuolisation. (C) and (D) electron microscopy showing numerous myelin-like lamellar figures within glomerular epithelial, mesangial and endothelial cells, and also tubular epithelial cells

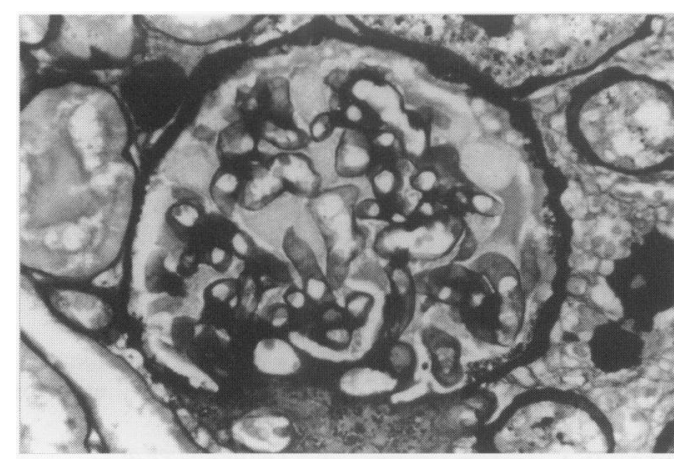

A

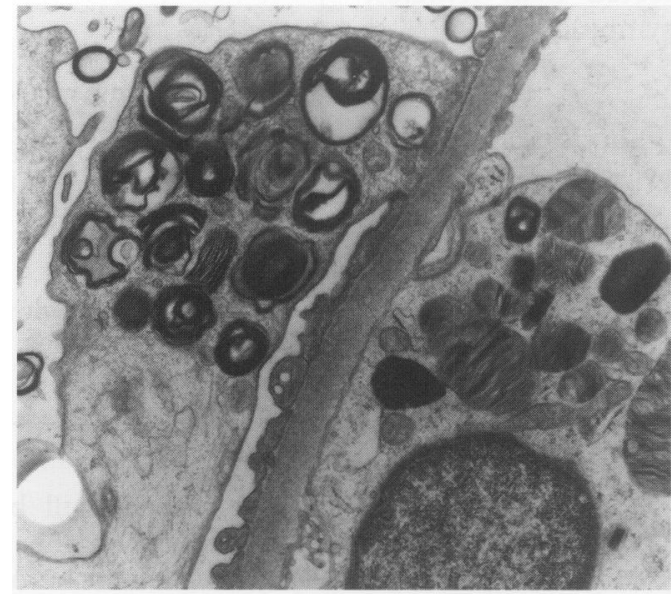

C
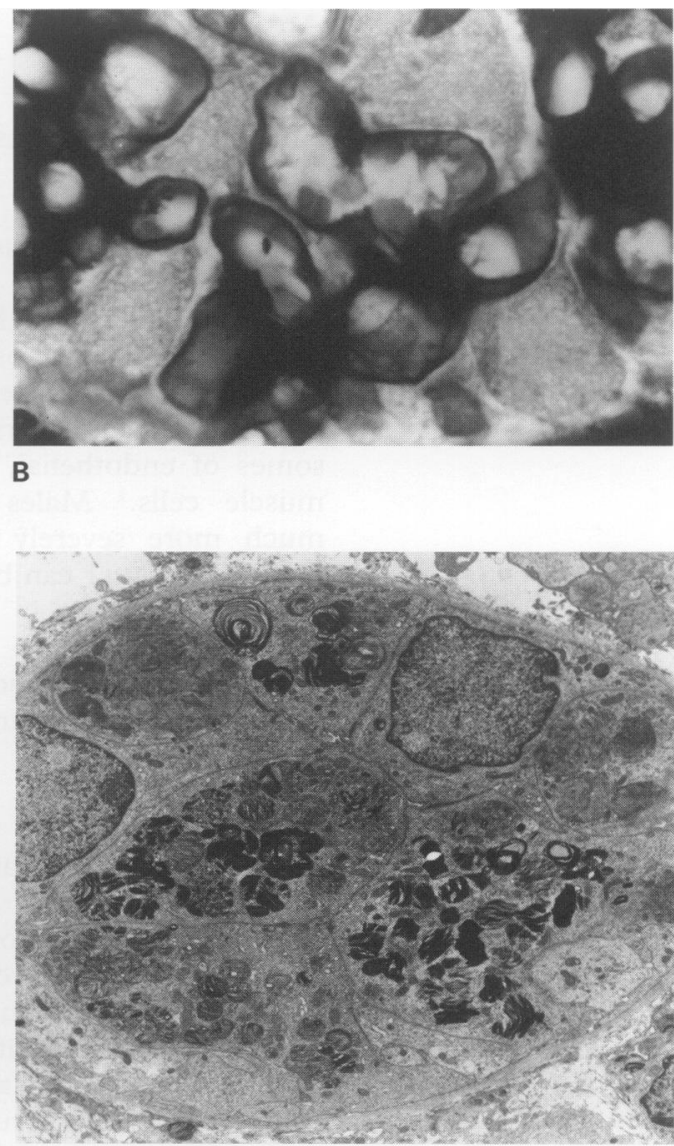

D

A renal biopsy was performed without complication. This contained 18 glomeruli, three of which were sclerosed, while the remainder had diffuse marked birefringent vacuolisation of visceral epithelial cells (figure $2 \mathrm{~A}$ ). There was also widespread tubular epithelial vacuolisation (figure $2 \mathrm{~B}$ ). Immunofluorescence was positive for $\operatorname{IgM}(++), \mathrm{Cl}_{\mathrm{q}}(++)$ and $\mathrm{C}_{3}(+++)$ focally and segmentally in glomerular capillary basement membranes and mesangium. Electron microscopy showed numerous myelin-like lamellar figures within glomerular epithelial, mesangial and endothelial cells, and also tubular epithelial cells (figure 2C and D).

\section{Questions}

1 What is the likely unifying diagnosis?

2 What is the underlying defect, and how is this condition inherited?

3 How are the nervous, renal and cardiovascular systems, and eye and skin, involved?

4 What treatment is available, and what is the prognosis? 
Answers

OUESTION 1

Anderson-Fabry disease

QUESTION 2

Anderson-Fabry disease is an X-linked recessive inborn error of metabolism caused by reduced activity of the lysosomal hydrolase enzyme, alpha-galactosidase $A$, which leads to accumulation of uncleaved glycosphingolipids (mainly trihexosyl ceramide) within the lysosomes of endothelial, perithelial and smooth muscle cells. ${ }^{1}$ Males (ie, hemizygotes) are much more severely affected than females, though the latter can be symptomatic.

\section{QUESTION 3}

The effects of Anderson-Fabry disease on the nervous, renal and cardiovascular systems are shown in the box.

\section{QUESTION 4}

Phenytoin or carbamazepine can be given for the acroparasthesiae, and antibiotic prophylaxis is necessary for dental and surgical procedures if a cardiac valvular lesion is present. Antihypertensives are given where blood pressure is elevated. Aspirin is advocated as a logical prophylactic agent against the consequences of vascular endothelial cell damage in some centres. ${ }^{2}$

Before dialysis and renal transplantation were available, hemizygotes rarely survived beyond 50 years of age, ${ }^{2,3}$ mainly succumbing to uraemia. Renal transplantation is successful, though the graft does not provide enough enzyme to be clinically helpful to other affected organs. Enzyme replacement therapy has been tried, though without uniform success to date. When recombinant enzyme production is

1 Desnick RJ, Ioannou YA, Eng CM. $\alpha$-Galactosidase A deficiency: Fabry's disease. In: Scriver CR, Beaudet AL, Sly WS, Valle $\mathrm{D}$, eds. The metabolic and molecular basis of inherited disease, 7th edn, vol 2. New York: McGraw Hill, 1995; pp 2741-84.

2 Morgan SH, Rudge P, Smith SJM, et al. The neurological complications of Anderson-Fabry disease (alpha-galactosicomplicaticien - in symptomatic patients. $Q \mathcal{F}$ Med 1990; 75: 491-504.

\begin{tabular}{l} 
Anderson-Fabry disease: features \\
\hline Neurological \\
- episodic painful crises \\
- acroparasthesiae \\
- autonomic neuropathy (leading to diarrhoea \\
and hypohydrosis) \\
- cerebrovascular disease \\
Ophthalmological \\
- cornea verticillata \\
- conjunctival angiokeratomata \\
Dermatological \\
- angiokeratomata (typically in 'bathing trunk' \\
distribution) \\
Nephrological \\
- proteinuria \\
- abnormal urinary sediment ('Maltese cross' \\
myelin bodies on polarised light microscopy) \\
- renal tubular dysfunction \\
progressive renal failure \\
Cardiological \\
- short PR interval \\
- mitral regurgitation \\
\end{tabular}

available there will be the hope of dramatic improvement in the prognosis of this condition; it will then be of paramount importance to achieve early diagnosis, before extensive organ damage from sphingolipid accumulation has occurred.

Genetic counselling should be offered.

\section{Final diagnosis}

Anderson-Fabry disease.

Keywords: Anderson-Fabry disease

3 Morgan SH. Anderson-Fabry disease and other inherited metabolic storage disorders with significant renal involvement. In: Cameron JS, Kerr DNS, Rees A, eds. Oxford textbook of clinical nephrology. Oxford University Press, 1992; ch 18.4.2. 